Article

\title{
Lambda Value at Risk and Regulatory Capital: A Dynamic Approach to Tail Risk
}

\author{
Asmerilda Hitaj ${ }^{1}$ (D), Cesario Mateus ${ }^{2}$ (iD) and Ilaria Peri ${ }^{3, *(D)}$ \\ 1 Department of Statistics and Quantitative Methods, University of Milan Bicocca, U7, \\ Via Bicocca degli Arcimboldi 8, Milan 20126, Italy; asmerilda.hitaj1@unimib.it \\ 2 Department of Accounting and Finance, University of Greenwich, Old Royal Naval College, Park Row, \\ London SE10 9LS, UK; C.Mateus@greenwich.ac.uk \\ 3 Department of Economics, Mathematics and Statistics, Birkbeck University of London, Malet St, Bloomsbury, \\ London WC1E 7HX, UK \\ * $\quad$ Correspondence: i.peri@bbk.ac.uk; Tel.: +44-20-7631-6000
}

Received: 17 January 2018; Accepted: 1 March 2018; Published: 6 March 2018

\begin{abstract}
This paper presents the first methodological proposal of estimation of the $\Lambda V a R$. Our approach is dynamic and calibrated to market extreme scenarios, incorporating the need of regulators and financial institutions in more sensitive risk measures. We also propose a simple backtesting methodology by extending the $V a R$ hypothesis-testing framework. Hence, we test our $\Lambda V a R$ proposals under extreme downward scenarios of the financial crisis and different assumptions on the profit and loss distribution. The findings show that our $\Lambda V a R$ estimations are able to capture the tail risk and react to market fluctuations significantly faster than the $V a R$ and expected shortfall. The backtesting exercise displays a higher level of accuracy for our $\Lambda V a R$ estimations.
\end{abstract}

Keywords: banking regulation; financial risk management; risk modelling; value at risk

JEL Classification: C53; G01; G32

\section{Introduction}

The global financial crisis has made risk measurement and its backtesting a primary concern for regulators and financial institutions. Over the past two decades, the value at risk $(\mathrm{VaR})$ has become the most popular method to assess the risk exposure of financial investments. One of the reasons for its widespread use is that the Basel Committee on Banking Supervision (1996a) has suggested that banks use an internal $V a R$ model for the calculation of their regulatory capital. Thus, authorities around the world have endorsed $V a R$ as the best practice or as a regulatory standard.

Despite its popularity, $V a R$ has been extensively criticized by academics. For instance, Artzner et al. $(1997,1999)$ have underlined some of the theoretical shortcomings of $V a R$ as a risk measure. Specifically, $V a R$ might penalize diversification since it is not subadditive and does not capture the tail risk. This is so because it does not consider losses greater than the VaR amount. In addition, the recent global financial crisis has highlighted the lack of sensitivity of the $V a R$. Financial risk managers have addressed the difficulty of a rapid adjustment of its confidence levels. As a consequence, $V a R$ may lead to under-forecasting of risk estimates before the crisis or even over-forecasting of them post-crisis.

Therefore, both regulators and financial institutions have recently increased their interest in more sensitive risk measures and their backtesting. In particular, the Minimum Capital Requirements for Market Risk by the Basel Committee (2016) has proposed to move to the expected shortfall (ES), known also as conditional value at risk ( $C V a R)$, which was introduced by Artzner et al. (1997). This measure of risk, which is defined as the expected value of losses exceeding $V a R$, can solve some of 
the issues with the $V a R$ and has sounder theoretical properties (i.e., it fulfills subadditivity). However, many studies have pointed out the challenges of delivering a robust forecasting and backtesting of the ES (see Gneiting 2011; Embrechts and Hofert 2014). Additional concerns about the ES backtesting are expressed by the Basel Committee (2016), which requires that the backtesting regulatory framework will still be based on $V a R$.

In a recent paper by Frittelli et al. (2014), a new risk measure is proposed: the lambda value at risk (lambdaVaR or $\Lambda V a R$ ) as a generalization of the $V a R$. The novelty of the $\Lambda V a R$ is considering a function $\Lambda$ that depends on the profits and losses (P\&Ls) of the risk factors, instead of a constant confidence level $\lambda$. For how it is built, the $\Lambda V a R$ assigns more risk to heavy-tailed P\&L distributions and less in the opposite case. Thus, the $\Lambda V a R$ should be able to discriminate the risk among assets with the same $V a R$ at level $\lambda$ but different tail behaviour of the P\&L distribution. However, in this theoretical paper, there is no explanation of how the $\Lambda V a R$ should be computed. The function $\Lambda$ can be either increasing or decreasing, but the authors do not propose any particular shape of the $\Lambda$ function or a method for its estimation.

The objective of this study is twofold: first, to provide a methodological proposal of estimation for the $\Lambda V a R$ and, second, to test its effectiveness as a regulatory alternative to $V a R$. Our methodological approach makes the $\Lambda V a R$ able to incorporate the actual market conditions, allowing for the reservation of more capital in crisis periods and less in normal market situations. We base the computation of the $\Lambda$ function on order statistics of the historical distribution function of some selected market benchmarks. The parameters are recalculated for each out-of-sample period, allowing the $\Lambda V a R$ to capture the market changes and assess the different reactivity of the assets to the market variations. Thus, our $\Lambda V a R$ estimations are able to discriminate the risk among assets with different tail behaviour in respect to the market. In addition, the $\Lambda V a R$ can be specified differently according the particular risk profile. We call this method of estimation, 'dynamic benchmark approach'. We also propose a simple backtesting methodology by extending the VaR hypothesis-testing framework by Kupiec (1995) to the $\Lambda V a R$ in order to have an initial evaluation of the $\Lambda V a R$ accuracy ${ }^{1}$.

We test our $\Lambda V a R$ effectiveness as a regulatory alternative to $V a R$ under extreme downward scenarios of the financial crisis and different assumptions on the P\&L distribution. We compare these estimates with those of the $V a R$ and the $E S$, highlighting the different levels of reactivity to bad changes in financial markets. Hence, we perform a backtesting exercise where we compare $V a R$ and $\Lambda V a R$ estimations' accuracy.

The remainder of the paper is organized as follows. Section 2 describes the new risk measure, the $\Lambda V a R$, from a theoretical point of view, and our proposal of estimation. Here, the backtesting methodology is also illustrated. Section 3 shows the results of the empirical test, consisting in the computation, backtesting, and comparison of the risk measures. Section 4 concludes.

\section{Method}

\subsection{Current Risk Measures and $\Lambda V a R$}

Because of its simple formulation and interpretation, the $V a R$ is the most popular tool for measuring financial risk. Let $X$ be the random variable that models asset returns (i.e., profit and loss, $\mathrm{P} \& \mathrm{~L})$ and $F(x)=P(X \leq x)$ its cumulative distribution function. We denote by $\mathcal{P}$ the set of all the distributions. The $V a R$ of a financial asset at the confidence level $\lambda$, where $0<\lambda<1$, is defined as the $\lambda$-right quantile of its P\&L distribution over a certain holding period. Formally,

$$
\operatorname{VaR}_{\lambda}(X)=-\sup \{x: F(x) \leq \lambda\}
$$

1 See Corbetta and Peri (2017) for a detailed study on the backtesting of the $\Lambda V a R$. The authors improved on the backtesting of the $\Lambda V a R$ and based their empirical findings on the $\Lambda V a R$ estimation proposal introduced in the current paper. 
In other words, $V a R_{\lambda}$ represents the maximum loss $x$ that may occur such that the probability of losing more than the amount $x$ is lower than $\lambda$ over a certain time horizon. The main advantage of the $V a R$ is that a single number immediately provides the idea of the amount of capital that should be allocated to cover the risk of a financial asset. On the other hand, the $V a R$ has many critics. Academics have pointed out that $\mathrm{VaR}$ might penalize diversification because of its lack of subadditivity; that is, the risk of the portfolio in terms of the $V a R$ may be larger than the sum of the risks of its components. In addition, practitioners have noticed its lack of sensitivity, especially during changes in the economic cycle. It seems to be difficult to rapidly decrease the confidence level when a crisis period occurs and to increase it post-crisis. Moreover, the $V a R$ does not allow practitioners to discriminate the risk of financial positions having the same $\lambda$-right quantile but a different tail thickness, thereby failing to capture extreme events.

The experiences from the global financial crisis have raised additional doubts about the accuracy of internal $\mathrm{VaR}$ models. These serious concerns have prompted the recent response by the Basel Committee (2016) to move to another risk measure known as the expected shortfall (ES), which was introduced by Artzner et al. (1997). Formally, the ES of an asset $X$ at confidence level $\lambda$, where $0<\lambda<1$, is given by

$$
E S_{\lambda}(X)=E\left[-X \mid X \leq-\operatorname{VaR}_{\lambda}(X)\right]=\frac{\int_{0}^{\lambda} \operatorname{VaR}_{s}(X) d s}{\lambda} .
$$

By definition, this risk measure is able to capture the tail risk. In addition, it does not discourage diversification since it satisfies the subadditivity property. However, several studies have found that the most significant issue associated with the $E S$ is the difficulty of achieving robust estimation and backtesting (see Gneiting 2011; Embrechts and Hofert 2014).

The new risk measure introduced by Frittelli et al. (2014), the $\Lambda V a R$, may be a valid alternative. The $\Lambda V a R$ is a generalization of the $V a R$ and is based on the fact that the confidence level can change and adjust according to the risk factor P\&L.

Specifically, it considers a function $\Lambda$ instead of a constant confidence level $\lambda$. Formally, given a monotone and right continuous function $\Lambda: \mathbb{R} \rightarrow\left[\lambda_{m}, \lambda_{M}\right]$ with $0<\lambda_{m} \leq \lambda_{M}<1$, the $\Lambda V a R$ of the asset return $X$ is a generalized quantile represented by the map $\Lambda V a R: \mathcal{P} \rightarrow \mathbb{R}$ defined as follows:

$$
\Lambda \operatorname{VaR}(F):=-\sup \{m \in \mathbb{R} \mid F(x) \leq \Lambda(x), \forall x \leq m\} .
$$

Intuitively, the $\Lambda V a R$ of the financial position $X$ is given by the smallest intersection between $F$ and $\Lambda$ if both are continuous. The function $\Lambda$ plays a key role in the definition of the $\Lambda V a R$ and adds flexibility. From a theoretical point of view, no particular properties are required by $\Lambda$, which can be either increasing or decreasing. In addition, $\Lambda V a R$ satisfies the mathematical properties of interest from a risk management point of view (Burzoni et al. 2017; Frittelli et al. 2014).

In Section 2.2, we propose a methodology to compute the $\Lambda V a R$, and we explain our $\Lambda$ choices, the assumptions behind them, and the empirical implications. See Figure 1 for a clearer understanding of this. 

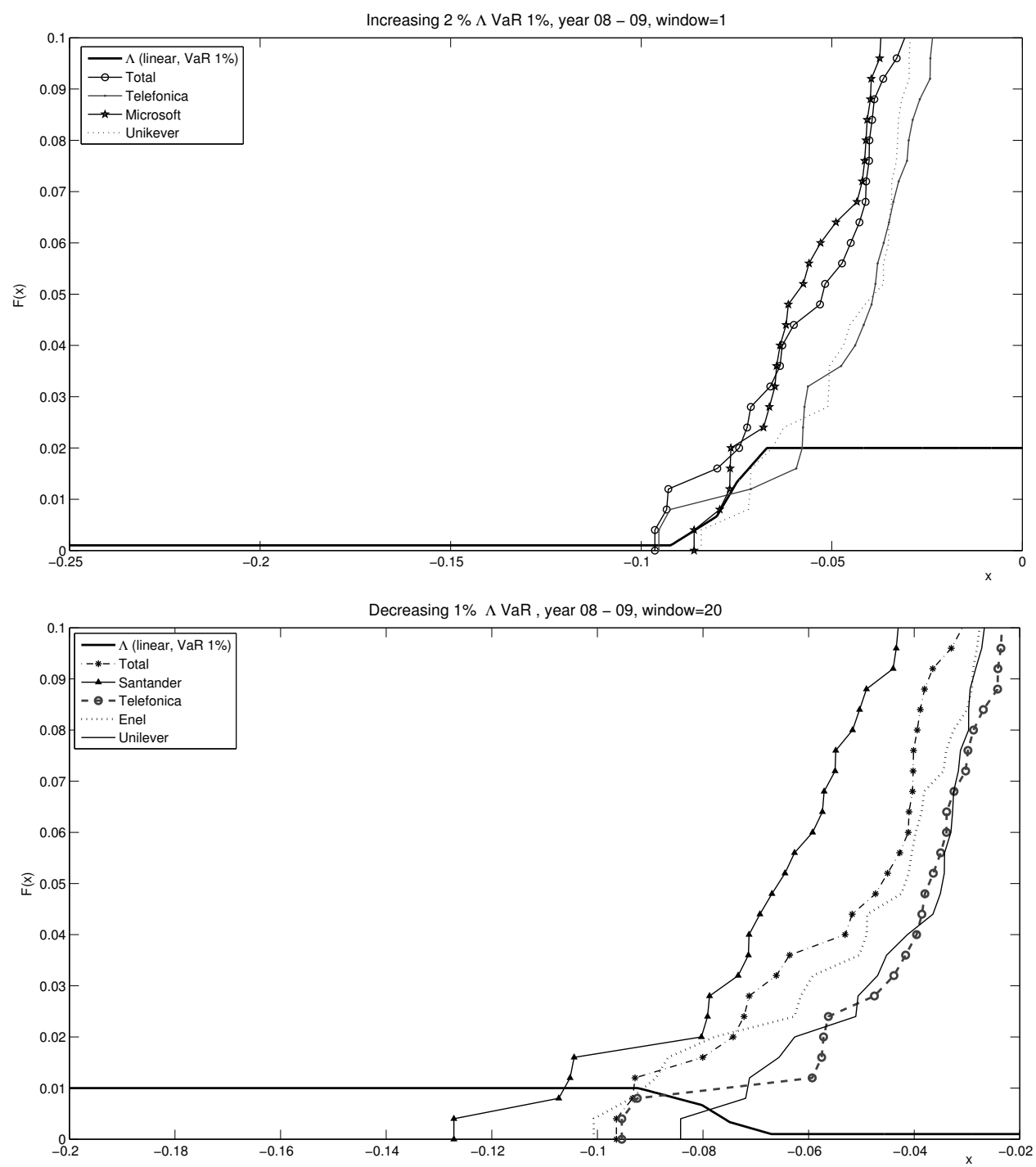

Figure 1. Increasing and decreasing $\Lambda V a R . \Lambda V a R$ coincides with the smallest intersection between the P\&L distribution and the $\Lambda$ function. $\Lambda V a R$ is able to capture different tail behaviour of return distributions better than $V a R$. For instance, in the figure on the top, Total has thicker tails than Microsoft. They have the same $2 \% \operatorname{VaR}(\cong 0.075)$ but Total's $2 \% \Lambda V a R(\cong 0.1)$ is higher than Microsoft's $2 \% \Lambda V a R$ $(\cong 0.0875)$. In the figure at the bottom, the same happens for Telefonica and Unilever.

\subsection{The Proposal of $\Lambda$ VaR Estimation: A Dynamic Benchmark Approach}

This section contains a guide to the estimation of the $\Lambda V a R$ and our methodological proposal. As discussed in Section 2.1, the flexibility of the $\Lambda V a R$ stems from the possibility of choosing the function $\Lambda$ instead of fixing a confidence level $\lambda$. From a theoretical point of view, $\Lambda$ is a right continuous function taking values on the interval $\left[\lambda_{m}, \lambda_{M}\right]$ with $0<\lambda_{m} \leq \lambda_{M}<1$. No additional constrictions are required on this function, which can be either increasing or decreasing.

The estimation of the $\Lambda V a R$ consists in four main steps: 1 . fixing the $\Lambda$ range of values, $\left[\lambda_{m}, \lambda_{M}\right]$; 2. deciding the $\Lambda$ direction (increasing or decreasing); 3 . choosing the $\Lambda$ functional shape; 4 . estimating the $\Lambda$ parameters.

Concerning the choice of the $\Lambda$ range of values, we first fix the minimum $\lambda_{m}$ close to 0 , specifically 0.001; we have proved, computationally, that a further reduction of $\lambda_{m}$ would determine an increase in the capital requirement without any benefit in terms of reduction in the number of violations. However, the main issue is the choice of the maximum, $\lambda_{M}$, that we call the $\Lambda V a R$ confidence level. This choice 
reflects the bank risk aversion profile. Common opinion and empirical evidence have shown a level of doubt about high confidence levels for the $V a R$. In addition, the Basel Committee has recently proposed the calibration of new risk measures for extreme scenarios. This might suggest considering a confidence level below $1 \%$. Hence, our first choice is $\lambda_{M}$ equal to $1 \%$, defining $1 \% \Lambda V a R$. However, from a managerial point of view, banks may consider the use of new risk measures that release capital in the case of higher confidence levels. For this reason, in Section 3, we also examined a $\Lambda V a R$ with $\lambda_{M}$ values equal to $1.5 \%$ and $2 \%$.

Regarding the second step, we suggest that the decision on the $\Lambda$ direction should be taken according to the expectation about the economic cycle. In the case of a bearish market trend, increasing function $\Lambda$ should make it easier to detect downside scenarios and reduce the number of overdrafts between the realized P\&L and the $\Lambda V a R$ estimations. On the other hand, a decreasing $\Lambda$ may be more convenient in periods of expected growth, allowing for a reduction in the capital aside, which may boost the investments.

The third step consists in examining different functional forms of continuous $\Lambda$. In the increasing case, it turns out to be an immediate and, at the same time, sensible specification to have a $\Lambda$ function that is obtained by linear interpolation. Formally, we divide the real line of the P\&L and probabilities in $n+1$ intervals, where $n$ is the number of data points used for the interpolation. Let us denote with $\pi_{i}$ and $\lambda_{i}$, where $i=1,2, \ldots n$, the extremes of the interpolating intervals on the P\&L and probability axis, respectively. For any P\&L amount $x<\pi_{1}$, we fix $\Lambda(x)=\lambda_{1}=\lambda_{m}$, for $x \geq \pi_{n}$ we fix $\Lambda(x)=\lambda_{n}=\lambda_{M}$, and when $\pi_{1} \leq x<\pi_{n}$ we suggest that

$$
\Lambda(x)=\sum_{i=1}^{n-1} \mathbf{1}_{\left[\pi_{i}, \pi_{i+1}\right)}\left(\left(x-\pi_{i}\right) \frac{\lambda_{i+1}-\lambda_{i}}{\pi_{i+1}-\pi_{i}}+\lambda_{i}\right) .
$$

In the decreasing case, for $x<\pi_{1}$, we fix $\Lambda(x)=\lambda_{M}$, for $x \geq \pi_{n}$ we fix $\Lambda(x)=\lambda_{m}$, and when $\pi_{1} \leq x<\pi_{n}$ we fix $\Lambda$ as follows:

$$
\Lambda(x)=\sum_{i=1}^{n-1} \mathbf{1}_{\left[\pi_{i}, \pi_{i+1}\right)}\left(\left(x-\pi_{i}\right) \frac{\lambda_{n-i}-\lambda_{n-i+1}}{\pi_{i+1}-\pi_{i}}+\lambda_{n-i+1}\right) .
$$

The final step of the $\Lambda$ calibration consists of the estimation of $\lambda_{i}$ and $\pi_{i}$. Here, the financial manager's aversion or propensity towards the risk plays a crucial role. In the increasing case, more $\Lambda$ is shifted on the right of the P\&L axis, the $\Lambda V a R$ absolute value is larger, and the capital allocated as risk protection is thus larger. In the decreasing case, the situation is reversed; financial managers adopting a prudential approach may choose $\Lambda$ to be more translated on the left. These considerations have a direct impact on the choice of the points $\pi_{i}$. In particular, if the objective is to strengthen the capital requirement, the points $\pi_{i}$ will be arranged on the right, in the increasing case, or on the left, in the decreasing case; on the contrary, if the objective is to release capital, the points $\pi_{i}$ will be arranged more on the left, in the increasing case, or on the right, in the decreasing case.

First, we fix the points $\lambda_{i}$, adopting a neutral approach. With the exception of $\lambda_{1}$ and $\lambda_{n}$, which are fixed equal to the minimum $\left(\lambda_{m}=0.001\right)$ and maximum $\left(\lambda_{M}=0.01\right) \Lambda$ value, respectively, the other $\lambda_{i}$ values are determined by an equipartition of the interval $\left(0, \lambda_{M}\right]$, specifically $\lambda_{i}=\lambda_{M} /(n-1) \times(i-1)$ with $i=2, \ldots, n-1$. On the other hand, another scale that thickens the points close to the maximum $\lambda_{M}$ (or the minimum $\lambda_{m}$ ) would determine an increase (or decrease) of the concavity of the $\Lambda$ function between $\pi_{1}$ and $\pi_{n}$, and this would have an impact on the capital requirement depending on the $\Lambda$ direction. One could choose to modify the capital requirement by varying either the vertical coordinates (on the probability axis) or the horizontal coordinates (on the P\&L axis) of the $\Lambda$ function or even both. We prefer to maintain a neutral approach on the vertical coordinates of $\Lambda$ and provide different $\Lambda V a R$ specifications by varying only the horizontal coordinates as described in the paragraph below. However, there are no restrictions on this point and other solutions can be experimented, although the number of $a d$ hoc choices on the model should remain limited. 
Finally, we estimate the points $\pi_{i}$ using the following approach, which we call dynamic benchmark approach. We calibrate $\Lambda$ on the statistics of the tail historical distribution of selected benchmarks. The idea is to compare the tails of an asset P\&L distribution with a function $\Lambda$ that directly depends on the tails of the market historical distribution. In such a way, we make the capital requirement decision depend on the behaviour of the risk factor returns in comparison with market returns. With this choice, we expect that the $\Lambda V a R$ is able to incorporate the recent market changes and the particular asset reactions faster than other risk measures. This approach is dynamic since the $\Lambda$ function is continuously recalculated by using the same rolling window of the risk measure and maintained constant throughout the out-of-sample period. However, the $\Lambda$ function must be unique for each risk factor, so the calibration cannot depend on specific features of the assets under analysis.

We set the points $\pi_{i}$ on the basis of the $n$ order statistics of the benchmark historical P\&L distributions. We propose taking four points $\pi_{i}$, so $n=4$. In our opinion, this number of points represents a good trade-off between fitting accuracy and function parametric complexity. However, this choice does not substantially affect the results. We fix $\pi_{1}$ equal to the smallest order statistic; that is, the minimum of all the benchmark returns, $\pi_{1}=\min \left(r_{\min 1}, \ldots r_{\min j}, \ldots r_{\min B}\right)$, where $r_{\min j}$ is the minimum return of the $j$-th benchmark, and $B$ is the total number of benchmarks. We fix $\pi_{2}, \pi_{3}$, and $\pi_{4}$ equal to the maximum, mean, and minimum of their historical $\lambda \%-V a R$, respectively. The choice of the confidence level $\lambda$ for the benchmarks' $V a R$ depends on the risk aversion profile. In the case of an increasing $\Lambda$, a $5 \%-V a R$ represents a more prudential choice than a $1 \%-V a R$, since $5 \%$-VaR order statistics shift the $\Lambda$ function more to the right. The converse holds in the case of a decreasing $\Lambda$. The rolling window used for computing the $1-5 \%-V a R$ of the benchmarks should be the same used for computing the $V a R$ and $\Lambda V a R$ of the risk factors.

For instance, if we test the $\Lambda V a R$ on equity markets, good benchmark candidates are the equity indexes that have the highest volume of transactions and that represent the markets in which the bank's trading activity is concentrated. In our empirical test, we selected the S\&P500 (US), the FTSE 100 (UK), and the EURO STOXX 50 (Eurozone). Alternatively, the selection of these benchmarks as well as the interval of confidence for their $V a R$ computation can be done externally by the regulator. Figure 1 shows two examples of the $\Lambda V a R$ estimations for the increasing and decreasing cases.

In conclusion, more advanced and sophisticated $\Lambda$ estimations may be considered provided that the mathematical properties of the $\Lambda V a R$ are preserved. However, increasing the $\Lambda$ complexity is not consistent with the purpose of this study. Our benchmark approach is easy to compute and allows for a better understanding of the new risk measure.

\subsection{Backtesting Method}

The reliability and accuracy of a risk measure depend on its ability to predict and cover future unexpected losses. For this reason, the risk measure should be backtested with appropriate methods. According to the Basel Committee on Banking Supervision (1996b), the backtesting, that is, the statistical procedure of comparing realized profits and losses $y$ with forecast risk measures $x$, is essential in the validation process of risk management internal models (see Jorion 2007).

The Basel Committee on Banking Supervision (1996b) has set up a regulatory backtesting framework for internal $\mathrm{VaR}$ models in order to monitor the frequency of exceptions; this is known as the traffic light approach. This procedure is carried out by comparing the last 250 daily $1 \% \mathrm{VaR}$ estimates with the corresponding daily P\&L outcomes. The accuracy of the model is then evaluated by counting the number of exceptions during this period. Many alternative proposals have been introduced in the literature for VaR (see Campbell 2005; Christoffersen 2010; Berkowitz et al. 2011 for a detailed review). On the other hand, the backtesting of $\Lambda V a R$ has been studied only recently by Corbetta and Peri (2017).

In this paper, we propose using, for the backtesting of the risk measures, the unilateral hypothesis test by Kupiec (1995), which is the first VaR method introduced in the literature and is the most widely known and used. This is also one of the simplest tests in that it allows for an intuitive interpretation and 
comparison of the $V a R$ and $\Lambda V a R$ backtesting performances. Kupiec's test, known as unconditional coverage (UC) or portion of failure (POF) test, measures whether the number $n$ of exceptions $y<x$ over a specific number of observations $N$ in the backtesting window is consistent with the confidence level $\lambda$. The $V a R$ model should be accepted if the frequency of exceptions over the specific time interval, $\hat{\lambda}$, does not significantly differ from the confidence level, $\lambda$. Hence, the null and the alternative hypothesis for the POF test are given by

$$
H_{0}: \lambda=\hat{\lambda}=\frac{n}{N}, \quad H_{1}: \hat{\lambda}>\lambda
$$

Under $H_{0}$, where the $\mathrm{VaR}$ is considered to be 'correct', the number of exceptions over the selected time period follows a binomial distribution. Thus, the POF test is conducted with the following log-likelihood ratio:

$$
L R_{P O F}=-2 \ln \left(\frac{(1-\lambda)^{N-n} \lambda^{n}}{\left(1-\left(\frac{n}{N}\right)\right)^{N-n}\left(\frac{n}{N}\right)^{n}}\right) \sim \chi_{1}^{2} .
$$

Asymptotically, as the number of observations $N$ goes to infinity, the test will be distributed as a $\chi^{2}$ with 1 degree of freedom. If the $L R_{P O F}$ statistic exceeds the critical value of the $\chi_{1}^{2}$, the model should be rejected. This critical level depends on the test confidence level. However, the choice of the confidence level is based on the balance of two types of errors: a type I error to reject a correct model and a type II error to accept an incorrect model. Increasing the significance level implies larger type I errors but smaller type II errors, and vice versa. Best practice suggests the use of a confidence level at least equal to $5 \%$ to control the type II errors, which can be very costly.

We extend the $V a R$ backtesting framework to the $\Lambda V a R$ while maintaining the same structure and fundamental meaning. Being a generalized quantile, the confidence level of the $\Lambda V a R$ changes according to the $\Lambda$ function. A good candidate for the $\Lambda V a R$ confidence level is the maximum of the $\Lambda$ function, $\max (\Lambda)$. Hence, we propose adjusting the POF test by considering the $\max (\Lambda)$, under the null hypothesis, instead of $\lambda$. In particular, the null and the alternative hypothesis for the $\Lambda V a R$ test become

$$
H_{0}: \frac{n}{N} \leq \max (\Lambda), \quad H_{1}: \frac{n}{N}>\max (\Lambda) .
$$

This is still an unilateral hypothesis test with the same critical region as the VaR test (see Casella and Berger 2002). Hence, it can be conducted by using the same log-likelihood ratio and critical value of the $V a R$ test. The risk model is validated if the relative number of the exceptions does not exceed the target level of exceptions given by $\max (\Lambda)$. This adjustment provides information about the $\Lambda V a R^{\prime} \mathrm{s}$ accuracy and an immediate interpretation. Indeed, it verifies whether the coverage objective given by the $\Lambda$ maximum has been reached. However, it has some limitations, which have been highlighted by Corbetta and Peri (2017) in their literature review. Here, we prescind from providing a complete framework on the backtesting of the $\Lambda V a R$.

\section{Empirical Analysis}

In this section, we test our methodology to compute the $\Lambda V a R$, the so-called dynamic benchmark approach, proposed in Section 2.2. We examine the different $\Lambda V a R$ specifications and their implementation under different assumptions of the P\&L distribution. We compare the $\Lambda V a R$ estimations with those of the $V a R$ and $E S$ and perform a backtesting exercise.

In particular, we want to test the ability of the risk measures to capture and react to extreme downward scenarios; for this reason, we chose data spanning over the global financial crisis. We compute the risk measures for a selection of stocks quoted in different developed countries that were severely affected by the crisis (the United States, the United Kingdom, Germany, France, Spain, and Italy) and are part of market indexes with the highest volume of stock exchanges; that is the S\&P500, the FTSE 100, and the EURO STOXX 50. In order to better understand the behaviour of the new risk measure, we select stocks from different industries (financial, utilities, communications, 
information technology, consumer staples, and energy) and with different responses to the market changes. These comprise the stocks of Citigroup Inc. (C UN Equity) and Microsoft Corporation (MSFT UW Equity) for the United States, Royal Bank of Scotland Group PLC (RBS LN Equity) and Unilever PLC (ULVR LN Equity) for the United Kingdom, Volkswagen AG (VOW3 GY Equity) and Deutsche Bank AG (DBK GY Equity) for Germany, Total SA (FP FP Equity) and BNP Paribas SA (BNP FP Equity) for France, Banco Santander SA (SAN SQ Equity) and Telefonica SA (TEF SQ Equity) for Spain, and Intesa Sanpaolo SPA (ISP IM Equity) and Enel SPA (ENEL IM Equity) for Italy. The dataset is composed of daily data from January 2005 to December 2011. The results of the descriptive statistics are collected in Table A1 of the Appendix A together with a brief discussion.

\section{Risk Measures Computation, Backtesting, and Comparison}

The first step of our analysis is to test our $\Lambda V a R$ specifications and compare its forecasts with the risk measures proposed by the current regulation, the $V a R$, and the ES. The aim is to evaluate the ability of the new risk measure to incorporate extreme downward scenarios and cover the risk of the trading book. For a complete analysis, we compare the $\Lambda V a R$ models in the previous section with three different $V a R$ models, one for each confidence level of $1 \%, 2 \%$, and $3 \%$. We add to the analysis the computation of the $E S$ at a $2.5 \%$ level of confidence, as recently suggested by the Basel Committee (2016). Specifically, we calculate the 1-day $V a R, \Lambda V a R$, and ES over a time horizon of 1 year (250 days) for the 12 equities previously described. In order to evaluate the behaviour and reactivity of the $\Lambda V a R$ to different market phases and compare it with the $V a R$ and $E S$, we compute the risk measures over the period from January 2005 to December 2011, which includes the evolution of the recent global financial crisis.

The robustness of our empirical results is assessed by conducting three simulation studies concerning different assumptions of the P\&L distributions, using, specifically, Monte Carlo Normal models, historical simulations, and GARCH models with Student- $t$ increments. We have chosen the historical simulation technique since it is widely used by practitioners who appreciate its model-free nature. GARCH models of the returns are vastly assumed in the finance and economics literature (among others see Engle 2001; Engle et al. 2008; Samitas and Kampouris 2017). The Monte Carlo simulation exercise consists of the generation of 10,000 values for the P\&L distribution. The simulations are based on the estimation of the parameters over the last $250 \mathrm{P} \& \mathrm{~L}$ observations for the historical and Normal assumptions, while 500 P\&L observations are considered for the GARCH approach.

The second objective of this analysis is to gauge the $\Lambda V a R^{\prime}$ s accuracy in comparison to the $V a R$. Hence, we conduct a backtesting exercise for the $V a R$ and $\Lambda V a R$ models. We compare the realized ex-post daily P\&L with the daily $V a R / \Lambda V a R$ estimates over a time period of a year. In particular, we split the analysis into six different two-year rolling windows (250 days for the risk measure computation and one year for the backtesting). We perform the backtesting method described in Section 2.3 for all of the 12 stocks and the $\Lambda V a R$ and $V a R$ models previously specified.

Figure 2 exhibits the first fundamental result of this analysis: the $\Lambda V a R$ is the most prudential approach and has the highest reactivity to market conditions. This figure displays the realized out-of-sample P\&L and the risk measures under historical simulation; specifically, the $1 \% V a R$, $1 \% \Lambda V a R$, and $2.5 \% E S$ for a significant sample of the selected equities during the different phases of the recent financial crisis. During the 2008 crisis year, the $\Lambda V a R$ is more conservative and reacts to adverse market conditions faster than the other risk measures. During the first year after the crisis, the $\Lambda V a R$ maintains the most prudential approach and guarantees the highest reactivity to unexpected downturns (i.e., Volkswagen). However, in the more stable periods before 2007, the behaviour of the $\Lambda V a R$ is in line with the behaviour of the $1 \% \mathrm{VaR}$ and $2.5 \% \mathrm{ES}$ in preserving the highest risk protection. 

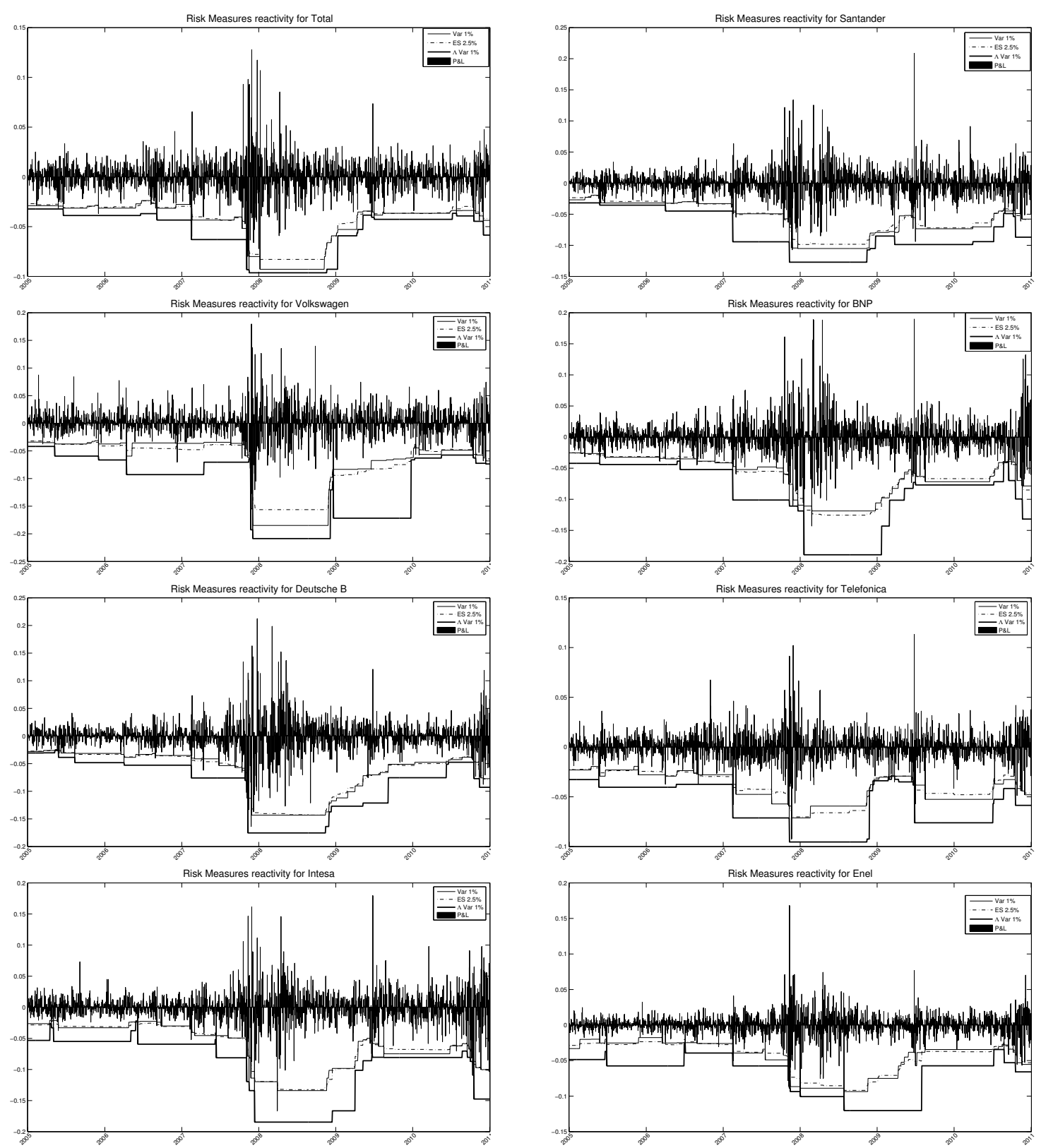

Figure 2. Different reactivity to market fluctuations of $V a R, E S$ and $\Lambda V a R$ under historical simulation. The $\Lambda V a R$ is the most conservative measure and has higher reactivity to adverse market conditions than the $V a R$ and the ES. Its behaviour is in line with the other risk measures during stable periods.

The backtesting exercise shows the second fundamental result of our analysis: the $\Lambda V a R$ has the highest accuracy. We discuss the backtesting results under the assumption of historical simulation of the P\&L distributions. In order to provide an overview of the model's accuracy and show the robustness of the backtesting results, we aggregate the POF test outcomes and violations at the level of the $V a R$ as well as the increasing and decreasing $\Lambda V a R$ models. Table 1 reports the evolution over time of the average number of violations and the POF acceptance rate for each of the risk models.

During 2006, the POF null hypothesis is always accepted for the $1 \%$ and $2 \% V a R$ and for the $\Lambda V a R$ models. The inaccuracy of the VaR models increases when the confidence level increases. During the US subprime crisis of August 2007, we observe a significant decrease in the acceptance rate for all the VaRs together with the decreasing $\Lambda V a R$ models, moving from 97 to $72 \%$ and from 100 to $83 \%$ on average, respectively. Contrary to this, the increasing $\Lambda V a R$ models maintain a $100 \%$ acceptance 
rate. The impact of the global financial crisis in 2008 highlights the significantly higher reactivity of the $\Lambda V a R$ models. The table displays a severe underestimation of the risk for all the VaR models, with the POF test acceptance rate equal to $0 \%$. Contrary to this, the POF acceptance rate stays at $100 \%$ for all of the increasing $\Lambda V a R$ models, even though the decreasing $\Lambda V a R$ models are less accurate during the crisis, with an average acceptance rate of $54 \%$ and $46 \%$ for the $1 \% \Lambda V a R$ and $1.5 \% \Lambda V a R$, respectively. The evolution of the average number of violations supports these considerations. The $1 \% \operatorname{VaR}$ model, in spite of having the highest accuracy among the other $V a R s$, shows a drastic increase in the average number of violations, moving from 3.42 in 2006 to 11.58 in 2008 . On the other hand, the increasing $\Lambda \mathrm{VaR}$ models register an average number of violations of around 1.17 during 2006 and retain a number of around 3.92 during the 2008 crisis. During 2009, the first response by the VaR models comes from the $1 \% \mathrm{VaR}$. It starts to incorporate the effects of the crisis, reaching a $100 \%$ acceptance rate, whereas the $2-3 \% \mathrm{VaR}$ models persistently underestimate the risk. The decreasing $\Lambda V a R$ models significantly increase their acceptance rate to $100 \%$ on average; the increasing $\Lambda V a R$ models maintain the best response to the crisis independently by the confidence level. During 2010, the other VaR models' acceptance rate increase to $87 \%$ on average, while the $\Lambda V a R$ models are comprehensively accepted. The 2011 economic downturn confirms the observations discussed before for 2008, with an extremely positive level of reactivity of the increasing $\Lambda V a R$ models in comparison to the decreasing $\Lambda V a R s$; however, the latter respond better than the $V a R s$. The trend of the average number of violations endorses these conclusions. Additional details about violations and Kupiec's POF for each of the equities and risk models are displayed in Appendix B. Due to space constraints, we only display the results of the 2008 crisis year.

Table 2 shows the results with the Monte Carlo and GARCH models with Student- $t$ increments. Notice that the Normal simulation approach has, in most of the cases, a lower average acceptance rate than the historical simulation and GARCH models. This is coherent with the results present in the literature that show that the Normal distribution does not fit the tails of the returns' distribution well. The GARCH model is the best approach to the $\Lambda V a R$ estimations outside the crisis, while historical models perform better during the crisis; the reason for this is that the historical distribution is computed using the returns realized in the previous 250 days, so it considers the downturn effect of the beginning of the crisis; this is not the case with the GARCH models, where the estimation of the parameters is based on the previous two years of observations. Regarding the performance of the $\Lambda V a R$ models with respect to the $V a R$, in terms of the average number of violations and the test acceptance rate, these results parallel the findings for the historical simulation case. The highest average acceptance rate of the $1.5 \%$ increasing $\Lambda \mathrm{VaR}$ models with respect to the $1 \%$ case is worth noting here. This may imply that a better approximation of the P\&L distribution allows for an increase in the interval of confidence of the $\Lambda V a R$ models.

To summarize, this empirical application highlights that our $\Lambda V a R$ models are able to capture downside risks and react to adverse market conditions faster than $V a R$ and ES models, thereby maintaining a behaviour in line with the other risk measures in more stable periods. In addition, the $\Lambda V a R$ models have a significantly higher level of accuracy than the VaR models. Specifically, the increasing $\Lambda V a R$ models register a higher performance in crisis periods. 
Table 1. Time evolution of the average number of violations and Kupiec test under the historical simulation assumption. The table shows the evolution over the global financial crisis of the average number of violations and the percentage of portion of failure (POF) acceptance, aggregated at the level of the $V a R$, as well as the increasing and decreasing $\Lambda V a R$ models.

\begin{tabular}{|c|c|c|c|c|c|c|c|c|c|c|c|c|c|}
\hline & & \multicolumn{6}{|c|}{ Violations (Historical Simulation) } & \multicolumn{6}{|c|}{ Kupiec's POF-Test (Historical Simulation) } \\
\hline & & $\begin{array}{c}2006 \\
(T=261)\end{array}$ & $\begin{array}{c}2007 \\
(\mathrm{~T}=259)\end{array}$ & $\begin{array}{c}2008 \\
(T=260)\end{array}$ & $\begin{array}{c}2009 \\
(T=261)\end{array}$ & $\begin{array}{c}2010 \\
(T=263)\end{array}$ & $\begin{array}{c}2011 \\
(T=264)\end{array}$ & 2006 & 2007 & 2008 & 2009 & 2010 & 2011 \\
\hline \multirow{4}{*}{$\operatorname{VaR}$} & $1 \%$ & 3.42 & 5.33 & 11.58 & 0.75 & 3.08 & 6.83 & $100 \%$ & $83 \%$ & $0 \%$ & $100 \%$ & $92 \%$ & $50 \%$ \\
\hline & $2 \%$ & 5.25 & 9.17 & 16.50 & 1.17 & 5.50 & 10.25 & $100 \%$ & $83 \%$ & $0 \%$ & $67 \%$ & $92 \%$ & $50 \%$ \\
\hline & $3 \%$ & 9.33 & 15.42 & 22.58 & 2.92 & 7.58 & 14.83 & $92 \%$ & $50 \%$ & $0 \%$ & $50 \%$ & $83 \%$ & $42 \%$ \\
\hline & & 6 & 9.97 & 16.89 & 1.61 & 5.39 & 10.64 & $97 \%$ & $72 \%$ & $0 \%$ & $72 \%$ & $89 \%$ & $47 \%$ \\
\hline \multirow{3}{*}{$\Lambda V a R 1 \%($ decr $)$} & linear (VaR 5\%) & 2.25 & 3.67 & 7.00 & 0.67 & 2.00 & 4.25 & $100 \%$ & $83 \%$ & $42 \%$ & $100 \%$ & $100 \%$ & $83 \%$ \\
\hline & linear (VaR 1\%) & 2.17 & 2.33 & 5.75 & 0.67 & 1.58 & 4.00 & $100 \%$ & $83 \%$ & $67 \%$ & $100 \%$ & $100 \%$ & $83 \%$ \\
\hline & & 2.21 & 3.00 & 6.38 & 0.67 & 1.79 & 4.13 & $100 \%$ & $83 \%$ & $54 \%$ & $100 \%$ & $100 \%$ & $83 \%$ \\
\hline \multirow{3}{*}{$\Lambda V a R 1 \%$ (incr) } & linear (VaR 5\%) & 1.17 & 1.00 & 3.92 & 0.42 & 0.92 & 2.75 & $100 \%$ & $100 \%$ & $100 \%$ & $100 \%$ & $100 \%$ & $100 \%$ \\
\hline & linear (VaR 1\%) & 1.17 & 1.00 & 3.92 & 0.42 & 1.00 & 2.75 & $100 \%$ & $100 \%$ & $100 \%$ & $100 \%$ & $100 \%$ & $100 \%$ \\
\hline & & 1.17 & 1.00 & 3.92 & 0.42 & 0.96 & 2.75 & $100 \%$ & $100 \%$ & $100 \%$ & $100 \%$ & $100 \%$ & $100 \%$ \\
\hline \multirow{3}{*}{$\Lambda V a R 1.5 \%$ (decr) } & linear (VaR 5\%) & 3.33 & 5.00 & 10.83 & 0.75 & 3.00 & 6.67 & $100 \%$ & $83 \%$ & $33 \%$ & $100 \%$ & $100 \%$ & $58 \%$ \\
\hline & linear (VaR 1\%) & 2.92 & 3.67 & 8.50 & 0.67 & 2.33 & 5.92 & $100 \%$ & $83 \%$ & $58 \%$ & $100 \%$ & $100 \%$ & $67 \%$ \\
\hline & & 3.13 & 4.33 & 9.67 & 0.71 & 2.67 & 6.29 & $100 \%$ & $83 \%$ & $46 \%$ & $100 \%$ & $100 \%$ & $63 \%$ \\
\hline \multirow{3}{*}{$\Lambda V a R 1.5 \%$ (incr) } & linear (VaR 5\%) & 1.17 & 1.00 & 3.92 & 0.42 & 0.92 & 2.75 & $100 \%$ & $100 \%$ & $100 \%$ & $100 \%$ & $100 \%$ & $100 \%$ \\
\hline & linear (VaR 1\%) & 1.17 & 1.00 & 3.92 & 0.42 & 1.00 & 2.83 & $100 \%$ & $100 \%$ & $100 \%$ & $100 \%$ & $100 \%$ & $100 \%$ \\
\hline & & 1.17 & 1.00 & 3.92 & 0.42 & 0.96 & 2.79 & $100 \%$ & $100 \%$ & $100 \%$ & $100 \%$ & $100 \%$ & $100 \%$ \\
\hline
\end{tabular}


Table 2. Time evolution of the average number of violations and Kupiec test under the Monte Carlo Normal and GARCH models. This table details the evolutions over the global financial crisis of the average number of violations and the percentage of POF acceptance, aggregated at the level of the $V a R$ and the increasing and decreasing $\Lambda V a R$ models.

\begin{tabular}{|c|c|c|c|c|c|c|c|c|c|c|c|c|c|}
\hline & & \multicolumn{6}{|c|}{ Violations (Montecarlo Normal) } & \multicolumn{6}{|c|}{ Kupiec's POF-Test (Montecarlo Normal) } \\
\hline & & 2006 & 2007 & 2008 & 2009 & 2010 & 2011 & 2006 & 2007 & 2008 & 2009 & 2010 & 2011 \\
\hline \multirow{4}{*}{$\operatorname{VaR}$} & $1 \%$ & 4.42 & 6.92 & 15.17 & 1.5 & 4.25 & 9.5 & $83 \%$ & $50 \%$ & $0 \%$ & $100 \%$ & $83 \%$ & $25 \%$ \\
\hline & $2 \%$ & 6.92 & 10 & 19.58 & 3 & 5.92 & 13.58 & $100 \%$ & $50 \%$ & $0 \%$ & $83 \%$ & $83 \%$ & $33 \%$ \\
\hline & $3 \%$ & 9.08 & 12.5 & 22.67 & 3.92 & 8 & 17.17 & $83 \%$ & $58 \%$ & $0 \%$ & $58 \%$ & $75 \%$ & $25 \%$ \\
\hline & & 6.81 & 9.81 & 19.14 & 2.81 & 6.06 & 13.42 & $89 \%$ & $53 \%$ & $0 \%$ & $81 \%$ & $81 \%$ & $28 \%$ \\
\hline \multirow{3}{*}{$\Lambda V a R 1 \%($ decr $)$} & linear (VaR 5\%) & 4.33 & 6.58 & 14.33 & 1.5 & 3.83 & 9.08 & $92 \%$ & $50 \%$ & $0 \%$ & $100 \%$ & $83 \%$ & $25 \%$ \\
\hline & linear (VaR 1\%) & 4.17 & 5.5 & 13 & 1.17 & 3.33 & 8.75 & $92 \%$ & $83 \%$ & $0 \%$ & $100 \%$ & $92 \%$ & $33 \%$ \\
\hline & & 4.25 & 6.04 & 13.67 & 1.33 & 3.58 & 8.92 & $92 \%$ & $67 \%$ & $0 \%$ & $100 \%$ & $88 \%$ & $29 \%$ \\
\hline \multirow{3}{*}{$\Lambda V a R 1 \%$ (incr) } & linear (VaR 5\%) & 1.83 & 2.67 & 8.33 & 0.75 & 1.58 & 5.17 & $100 \%$ & $92 \%$ & $25 \%$ & $100 \%$ & $100 \%$ & $58 \%$ \\
\hline & linear (VaR 1\%) & 1.92 & 3.83 & 10.17 & 1.08 & 2 & 5.58 & $100 \%$ & $75 \%$ & $8 \%$ & $100 \%$ & $92 \%$ & $58 \%$ \\
\hline & & 1.88 & 3.25 & 9.25 & 0.92 & 1.79 & 5.38 & $100 \%$ & $83 \%$ & $17 \%$ & $100 \%$ & $96 \%$ & $58 \%$ \\
\hline \multirow{3}{*}{$\Lambda V a R 1.5 \%($ decr $)$} & linear (VaR 5\%) & 5 & 7.92 & 16.17 & 2.17 & 4.75 & 11.08 & $92 \%$ & $58 \%$ & $0 \%$ & $100 \%$ & $92 \%$ & $33 \%$ \\
\hline & linear (VaR 1\%) & 4.83 & 6.67 & 13.67 & 1.75 & 4.08 & 10.42 & $92 \%$ & $83 \%$ & $8 \%$ & $100 \%$ & $100 \%$ & $33 \%$ \\
\hline & & 4.92 & 7.29 & 14.92 & 1.96 & 4.42 & 10.75 & $92 \%$ & $71 \%$ & $4 \%$ & $100 \%$ & $96 \%$ & $33 \%$ \\
\hline \multirow{3}{*}{$\Lambda V a R 1.5 \%$ (incr) } & linear (VaR 5\%) & 1.83 & 3.25 & 8.67 & 0.75 & 1.67 & 5.25 & $100 \%$ & $92 \%$ & $58 \%$ & $100 \%$ & $100 \%$ & $92 \%$ \\
\hline & linear (VaR 1\%) & 2.42 & 4.92 & 11.58 & 1.08 & 2.5 & 5.83 & $100 \%$ & $75 \%$ & $33 \%$ & $100 \%$ & $92 \%$ & $83 \%$ \\
\hline & & 2.13 & 4.08 & 10.13 & 0.92 & 2.08 & 5.54 & $100 \%$ & $83 \%$ & $46 \%$ & $100 \%$ & $96 \%$ & $88 \%$ \\
\hline
\end{tabular}


Table 2. Cont

\begin{tabular}{|c|c|c|c|c|c|c|c|c|c|c|c|c|c|}
\hline & & \multicolumn{6}{|c|}{ Violations (GARCH Model) } & \multicolumn{6}{|c|}{ Kupiec's POF-Test (GARCH Model) } \\
\hline & & 2006 & 2007 & 2008 & 2009 & 2010 & 2011 & 2006 & 2007 & 2008 & 2009 & 2010 & 2011 \\
\hline \multirow{4}{*}{$\operatorname{VaR}$} & $1 \%$ & 3 & 6.83 & 15.17 & 0.25 & 0.75 & 4.17 & $100 \%$ & $75 \%$ & $0 \%$ & $100 \%$ & $100 \%$ & $67 \%$ \\
\hline & $2 \%$ & 5 & 11.17 & 19.58 & 0.92 & 2.08 & 7.83 & $83 \%$ & $58 \%$ & $0 \%$ & $75 \%$ & $92 \%$ & $67 \%$ \\
\hline & $3 \%$ & 7.5 & 14.08 & 22.67 & 1.92 & 3.08 & 12.08 & $100 \%$ & $58 \%$ & $0 \%$ & $50 \%$ & $75 \%$ & $67 \%$ \\
\hline & & 5.17 & 10.69 & 19.14 & 1.03 & 1.97 & 8.03 & $94 \%$ & $64 \%$ & $0 \%$ & $75 \%$ & $89 \%$ & $67 \%$ \\
\hline \multirow{3}{*}{$\Lambda V a R 1 \%($ decr $)$} & linear (VaR 5\%) & 2.83 & 5.58 & 14.33 & 0.25 & 0.33 & 4.08 & $100 \%$ & $83 \%$ & $0 \%$ & $100 \%$ & $100 \%$ & $75 \%$ \\
\hline & linear (VaR 1\%) & 2.67 & 4.75 & 13 & 0.17 & 0.17 & 3.75 & $100 \%$ & $83 \%$ & $0 \%$ & $100 \%$ & $100 \%$ & $75 \%$ \\
\hline & & 2.75 & 5.17 & 13.67 & 0.21 & 0.25 & 3.92 & $100 \%$ & $83 \%$ & $0 \%$ & $100 \%$ & $100 \%$ & $75 \%$ \\
\hline \multirow{3}{*}{$\Lambda V a R 1 \%$ (incr) } & linear ( $\operatorname{VaR} 5 \%)$ & 0.5 & 0.75 & 8.33 & 0 & 0.25 & 0.58 & $100 \%$ & $100 \%$ & $25 \%$ & $100 \%$ & $100 \%$ & $100 \%$ \\
\hline & linear (VaR 1\%) & 0.5 & 1.17 & 10.17 & 0 & 0.5 & 0.75 & $100 \%$ & $100 \%$ & $8 \%$ & $100 \%$ & $100 \%$ & $100 \%$ \\
\hline & & 0.5 & 0.96 & 9.25 & $\mathbf{0}$ & 0.38 & 0.67 & $100 \%$ & $100 \%$ & $17 \%$ & $100 \%$ & $100 \%$ & $100 \%$ \\
\hline \multirow{3}{*}{$\Lambda V a R 1.5 \%$ (decr) } & linear (VaR 5\%) & 3.92 & 7.58 & 16.17 & 0.5 & 0.92 & 5.75 & $100 \%$ & $75 \%$ & $0 \%$ & $100 \%$ & $100 \%$ & $75 \%$ \\
\hline & linear (VaR 1\%) & 3.33 & 5.83 & 13.67 & 0.25 & 0.5 & 5.42 & $100 \%$ & $83 \%$ & $8 \%$ & $100 \%$ & $100 \%$ & $83 \%$ \\
\hline & & 3.63 & 6.71 & 14.92 & 0.38 & 0.71 & 5.58 & $100 \%$ & $79 \%$ & $4 \%$ & $100 \%$ & $100 \%$ & $79 \%$ \\
\hline \multirow{3}{*}{$\Lambda V a R 1.5 \%$ (incr) } & linear (VaR 5\%) & 0.5 & 0.83 & 8.67 & 0 & 0.5 & 0.67 & $100 \%$ & $100 \%$ & $58 \%$ & $100 \%$ & $100 \%$ & $100 \%$ \\
\hline & linear (VaR 1\%) & 0.5 & 1.58 & 11.58 & 0 & 0.67 & 0.83 & $100 \%$ & $100 \%$ & $33 \%$ & $100 \%$ & $100 \%$ & $100 \%$ \\
\hline & & 0.5 & 1.21 & 10.13 & 0 & 0.58 & 0.75 & $100 \%$ & $100 \%$ & $46 \%$ & $100 \%$ & $100 \%$ & $100 \%$ \\
\hline
\end{tabular}




\section{Conclusions}

The global financial crisis has made risk measurement and its backtesting a primary concern for regulators and financial institutions. Several issues concerning the $V a R$ and doubts raised about the $E S$ have caused us to examine alternative risk measures. A good candidate to overcome these issues seems to be the $\Lambda V a R$. This study presents the first methodological proposal of estimation of the $\Lambda V a R$.

We estimated the $\Lambda V a R$ based on order statistics of the distribution of certain selected market benchmarks. This approach allows the $\Lambda V a R$ to discriminate the risk among assets with different tail behaviour and capture the specific reactions to market fluctuations. In addition, the parameters of the $\Lambda V a R$ are constantly recalculated to incorporate changes in market conditions and can be specified according to different risk attitudes. We also propose backtesting methodology by extending the VaR hypothesis-testing framework.

We tested our approach under different assumptions of the P\&L distribution and during different phases of the global financial crisis. We experimented with different estimations of the $\Lambda V a R$ and used several confidence levels. The first finding displays the significant ability of the $\Lambda V a R$ estimates to capture extreme downward scenarios and react to financial market changes faster than the $V a R$ and $E S$. The results of the backtesting exercise display the significantly higher accuracy of our $\Lambda V a R$ specifications during different phases of the global financial crisis, increasing the confidence level up to $1.5 \%$. Results are confirmed using different assumptions on the P\&L distributions.

This study sheds some light on the importance of incorporating recent mark trends in the risk measure for assessing the bank capital requirement. This may lead to a prompt adjustment of the bank's capital to unexpected downturns and assure, overall, a higher stability of the financial system. Hence, the paper provides insights into the Basel Committee's reviews of the future role of internal models in determining the bank capital requirement. To this end, future research will be focused on the backtesting of the $\Lambda V a R$, the computation of the $\Lambda V a R$ with other risk factors, and the final aggregation of $\Lambda V a R$ values.

Author Contributions: The authors contribute equally to this article.

Conflicts of Interest: The authors declare no conflict of interest.

\section{Appendix A. Descriptive Statistics of the Dataset}

Table A1 provides the annual descriptive statistics of the daily logarithmic returns for all the stocks and indexes in each 1-year window throughout the financial crisis. The annual mean log returns vary significantly across the time windows. They are all positive in 2006, ranging from $1.46 \%$ for Citigroup to $53.31 \%$ for Volkswagen, whereas the annual standard deviation is quite small, with a maximum value of $28.84 \%$ for Volkswagen. As a consequence of the 2007 U.S. subprime mortgage crisis, all the annual mean returns of the financial equities show a significant drop, with the exception of Banco Santander. The minimum daily return was $-40.96 \%$ for the Royal Bank of Scotland on 7 October 2007 because of the large exposure to Lehman Brothers. During the 2008 global financial crisis, the fall of the annual mean returns encompassed all stocks and was accompanied by a significant increase in annual volatility. Unsurprisingly, the worst slumps in the annual mean returns were reported by the financial equities, in particular the Royal Bank of Scotland, $-219.88 \%$, and Citigroup, $-139.97 \%$, which also accounts for the highest annual volatility of $113.21 \%$. However, in 2010, the returns of Royal Bank of Scotland and Citigroup returned to positive values, whereas the effects of the financial crisis persisted in all Eurozone equities. In 2011, there was a further downturn in all of the equities' returns, with the exception of that of Unilever.

The skewness values are negative for many stocks and time windows, indicating that the empirical distributions of the stocks' daily returns are skewed to the left. The kurtosis values are well above 3 for all of the stocks and time windows, indicating deviations from the Normal distribution and the presence of fat tails. This is also confirmed by the Jarque-Bera (JB) test, which rejects the normality assumption at the $5 \%$ significance level for most of the stocks and time windows under investigation. 
Table A1. Annual descriptive statistics for the equities and indexes in each year under analysis. The dataset includes 12 stocks belonging to the S\&P500, the FTSE 100, and the EURO STOXX 50. The dataset contains six 1-year windows from January 2006 to December 2011. For each stock and index, we report the minimum daily return, the maximum daily return, the annual mean (the average daily return is annualized), the annual standard deviation (the daily standard deviation is annualized), skewness, kurtosis, the Jarque-Bera (JB) test statistic, and its null hypothesis $h\left(h=A\right.$ if $H_{0}$ is accepted and $h=R$ otherwise).

\begin{tabular}{|c|c|c|c|c|c|c|c|c|c|c|c|c|c|c|c|c|c|c|}
\hline \multicolumn{10}{|c|}{2006} & \multicolumn{9}{|c|}{2007} \\
\hline & $\begin{array}{l}\text { Min Daily } \\
\text { Return }\end{array}$ & $\begin{array}{c}\text { Max Daily } \\
\text { Return }\end{array}$ & $\begin{array}{c}\text { Annual } \\
\text { Mean }\end{array}$ & $\begin{array}{c}\text { Annual } \\
\text { std }\end{array}$ & Skewness & Kurtosis & JB & H & $p$-Value & $\begin{array}{c}\text { Min Daily } \\
\text { Return }\end{array}$ & $\begin{array}{c}\text { Max Daily } \\
\text { Return }\end{array}$ & $\begin{array}{c}\text { Annual } \\
\text { Mean }\end{array}$ & $\begin{array}{c}\text { Annual } \\
\text { std }\end{array}$ & Skewness & Kurtosis & JB & $\mathrm{H}$ & $p$-Value \\
\hline FP FP & -0.0388 & 0.0334 & 0.0326 & 0.1807 & -0.3998 & 3.6305 & 10.8004 & $\mathrm{R}$ & 0.0119 & -0.0434 & 0.0458 & 0.0131 & 0.2053 & 0.1085 & 3.6228 & 4.5312 & A & 0.0828 \\
\hline SAN SQ & -0.0354 & 0.0340 & 0.2265 & 0.1764 & -0.3483 & 3.6016 & 8.8246 & $\mathrm{R}$ & 0.0194 & -0.0450 & 0.0407 & 0.0157 & 0.2112 & -0.0848 & 3.7085 & 5.5288 & A & 0.0540 \\
\hline VOW3 GY & -0.0664 & 0.0875 & 0.5331 & 0.2884 & 0.6285 & 6.8101 & 167.6764 & $\mathrm{R}$ & 0.0010 & -0.0929 & 0.0775 & 0.6116 & 0.3010 & -0.0793 & 6.7672 & 148.0897 & $\mathrm{R}$ & 0.0010 \\
\hline BNP FP & -0.0441 & 0.0411 & 0.1838 & 0.2157 & -0.0998 & 3.2898 & 1.2895 & A & 0.4873 & -0.0522 & 0.0501 & -0.1345 & 0.2649 & 0.0604 & 3.7158 & 5.4897 & A & 0.0548 \\
\hline DBK GY & -0.0482 & 0.0416 & 0.2132 & 0.2055 & -0.3727 & 3.7980 & 12.4206 & $\mathrm{R}$ & 0.0084 & -0.0528 & 0.0419 & -0.1578 & 0.2347 & 0.0817 & 3.8776 & 8.3019 & $\mathrm{R}$ & 0.0222 \\
\hline TEF SQ & -0.0404 & 0.0362 & 0.2387 & 0.1532 & -0.2186 & 4.6203 & 29.3396 & $\mathrm{R}$ & 0.0010 & -0.0374 & 0.0675 & 0.3186 & 0.2018 & 0.3926 & 5.8767 & 92.6257 & $\mathrm{R}$ & 0.0010 \\
\hline ISP IM & -0.0550 & 0.0733 & 0.1883 & 0.2139 & 0.4339 & 6.5060 & 135.8837 & $\mathrm{R}$ & 0.0010 & -0.0594 & 0.0328 & -0.0882 & 0.1891 & -0.2301 & 5.0088 & 44.2408 & $\mathrm{R}$ & 0.0010 \\
\hline ENEL IM & -0.0575 & 0.0323 & 0.1554 & 0.1322 & -1.1327 & 12.4250 & 978.7849 & $\mathrm{R}$ & 0.0010 & -0.0394 & 0.0243 & 0.0257 & 0.1501 & -0.5195 & 4.3647 & 30.6449 & $\mathrm{R}$ & 0.0010 \\
\hline C UN & -0.0471 & 0.0300 & 0.0146 & 0.1619 & -0.4009 & 5.0078 & 48.6896 & $\mathrm{R}$ & 0.0010 & -0.0826 & 0.0680 & -0.6955 & 0.3012 & -0.1538 & 6.1061 & 101.4809 & $\mathrm{R}$ & 0.0010 \\
\hline MSFT UW & -0.1274 & 0.0560 & 0.0305 & 0.2274 & -2.4345 & 27.9181 & 6714.7750 & $\mathrm{R}$ & 0.0010 & -0.0481 & 0.0849 & 0.1039 & 0.2299 & 0.6769 & 7.4973 & 229.7779 & $\mathrm{R}$ & 0.0010 \\
\hline RBS LN & -0.0334 & 0.0400 & 0.1195 & 0.1571 & 0.3047 & 4.3665 & 23.3198 & $\mathrm{R}$ & 0.0014 & -0.4096 & 0.0879 & -0.8447 & 0.5197 & -7.4942 & 94.7552 & 90038.2373 & $\mathrm{R}$ & 0.0010 \\
\hline \multirow[t]{2}{*}{ ULVR LN } & -0.0599 & 0.0453 & 0.1291 & 0.1714 & -0.5139 & 7.4596 & 218.1719 & $\mathrm{R}$ & 0.0010 & -0.0347 & 0.0568 & 0.2977 & 0.2086 & 0.5671 & 4.4899 & 36.5219 & $\mathrm{R}$ & 0.0010 \\
\hline & \multicolumn{9}{|c|}{ Indexes' Statistics } & \multicolumn{9}{|c|}{ Indexes' Statistics } \\
\hline SPX Index & -0.0290 & 0.0220 & 0.0215 & 0.1234 & -0.2404 & 3.5449 & 5.5002 & A & 0.0545 & -0.0413 & 0.0313 & -0.0391 & 0.1644 & -0.5905 & 4.9352 & 53.5407 & $\mathrm{R}$ & 0.0010 \\
\hline SX5E Index & -0.0341 & 0.0264 & 0.1389 & 0.1461 & -0.4683 & 4.2074 & 24.3246 & $\mathrm{R}$ & 0.0013 & -0.0293 & 0.0289 & 0.0622 & 0.1591 & -0.2096 & 3.4765 & 4.1959 & A & 0.0965 \\
\hline UKX Index & -0.0244 & 0.0237 & 0.1210 & 0.1225 & -0.1826 & 4.0389 & 12.6325 & $\mathrm{R}$ & 0.0080 & -0.0438 & 0.0326 & -0.0387 & 0.1830 & -0.4193 & 4.3609 & 26.6163 & $\mathrm{R}$ & 0.0010 \\
\hline
\end{tabular}


Table A1. Cont.

\begin{tabular}{|c|c|c|c|c|c|c|c|c|c|c|c|c|c|c|c|c|c|c|}
\hline \multicolumn{10}{|c|}{2008} & \multicolumn{9}{|c|}{2009} \\
\hline & $\begin{array}{l}\text { Min Daily } \\
\text { Return }\end{array}$ & $\begin{array}{l}\text { Max Daily } \\
\text { Return }\end{array}$ & $\begin{array}{c}\text { Annual } \\
\text { Mean }\end{array}$ & $\begin{array}{c}\text { Annual } \\
\text { std }\end{array}$ & Skewness & Kurtosis & $\mathrm{JB}$ & H & $p$-Value & $\begin{array}{c}\text { Min Daily } \\
\text { Return }\end{array}$ & $\begin{array}{c}\text { Max Daily } \\
\text { Return }\end{array}$ & $\begin{array}{c}\text { Annual } \\
\text { Mean }\end{array}$ & $\begin{array}{c}\text { Annual } \\
\text { std }\end{array}$ & Skewness & Kurtosis & JB & H & $p$-Value \\
\hline FP FP & -0.0964 & 0.1279 & -0.3778 & 0.4800 & 0.5332 & 6.8048 & 162.6412 & $\mathrm{R}$ & 0.0010 & -0.0592 & 0.0854 & 0.0904 & 0.2942 & 0.1161 & 5.1276 & 47.7145 & $\mathrm{R}$ & 0.0010 \\
\hline SAN SQ & -0.1272 & 0.1339 & -0.7142 & 0.5410 & 0.1200 & 6.0451 & 97.1911 & $\mathrm{R}$ & 0.0010 & -0.0852 & 0.1257 & 0.5008 & 0.4566 & 0.2267 & 5.6305 & 74.2226 & $\mathrm{R}$ & 0.0010 \\
\hline VOW3 GY & -0.2086 & 0.1797 & -0.9460 & 0.6583 & -0.8299 & 10.4683 & 609.7016 & $\mathrm{R}$ & 0.0010 & -0.1717 & 0.1397 & 0.4458 & 0.5869 & -0.2108 & 5.3791 & 60.8111 & $\mathrm{R}$ & 0.0010 \\
\hline BNP FP & -0.1893 & 0.1613 & -0.9074 & 0.6240 & -0.1873 & 6.3064 & 115.3370 & $\mathrm{R}$ & 0.0010 & -0.1430 & 0.1887 & 0.5602 & 0.6176 & 0.8090 & 8.0523 & 293.1566 & $\mathrm{R}$ & 0.0010 \\
\hline DBK GY & -0.1754 & 0.2125 & -1.2575 & 0.7341 & 0.2452 & 7.3222 & 197.1055 & $\mathrm{R}$ & 0.0010 & -0.1269 & 0.1986 & 0.5447 & 0.6598 & 0.4548 & 5.8678 & 94.2840 & $\mathrm{R}$ & 0.0010 \\
\hline TEF SQ & -0.0954 & 0.1022 & -0.3257 & 0.3750 & 0.0187 & 6.6780 & 140.9284 & $\mathrm{R}$ & 0.0010 & -0.0377 & 0.0570 & 0.1916 & 0.2015 & 0.1586 & 4.1838 & 15.6458 & $\mathrm{R}$ & 0.0045 \\
\hline ISP IM & -0.1846 & 0.1614 & -0.7518 & 0.5905 & -0.1282 & 8.4487 & 309.9411 & $\mathrm{R}$ & 0.0010 & -0.1665 & 0.1460 & 0.2049 & 0.5107 & -0.3946 & 7.3550 & 204.0519 & $\mathrm{R}$ & 0.0010 \\
\hline ENEL IM & -0.1007 & 0.1682 & -0.6123 & 0.4222 & 0.5062 & 11.0113 & 679.2366 & $\mathrm{R}$ & 0.0010 & -0.1203 & 0.0743 & -0.0059 & 0.3460 & -0.8385 & 7.6000 & 249.7127 & $\mathrm{R}$ & 0.0010 \\
\hline C UN & -0.3049 & 0.42 & -1.3997 & 1.1321 & 0.4480 & 10.2519 & 556.1805 & $\mathrm{R}$ & 0.0010 & 0.4917 & 0.3188 & -0.8075 & 1.2630 & -0.5920 & 11.0411 & 688.1444 & $\mathrm{R}$ & 0.0010 \\
\hline MSFT UW & -0.0861 & 0.1665 & -0.5525 & 0.4995 & 0.7136 & 6.7986 & 171.5222 & $\mathrm{R}$ & 0.0010 & -0.1324 & 0.0887 & 0.3860 & 0.3617 & -0.5212 & 9.2412 & 417.0772 & $\mathrm{R}$ & 0.0010 \\
\hline RBS LN & -0.49 & & -2.1 & 1.0237 & -1.6843 & 18.3559 & 2574.4868 & $\mathrm{R}$ & 0.0010 & 57 & 0.3050 & -0.6 & 1.4588 & -6.4 & 80.8619 & 64901.8805 & $\mathrm{R}$ & 0.0010 \\
\hline \multirow[t]{2}{*}{ ULVR LN } & -0.0842 & 0.0717 & -0.1675 & 0.3922 & -0.0967 & 4.0791 & 12.5204 & $\mathrm{R}$ & 0.0082 & -0.0605 & 0.0936 & 0.2483 & 0.2625 & 0.5203 & 6.9602 & 174.6435 & $\mathrm{R}$ & 0.0010 \\
\hline & \multicolumn{9}{|c|}{ Indexes' Statistics } & \multicolumn{9}{|c|}{ Indexes' Statistics } \\
\hline SPX Index & -0.0872 & 0.1104 & -0.4517 & 0.4304 & 0.1654 & 5.6222 & 72.7629 & $\mathrm{R}$ & 0.0010 & -0.0517 & 0.0656 & 0.1518 & 0.2494 & 0.2158 & 5.2018 & 52.4405 & $\mathrm{R}$ & 0.0010 \\
\hline SX5E Index & -0.0821 & 0.1044 & -0.5932 & 0.3899 & & 6.5992 & 139.1742 & $\mathrm{R}$ & 0.0010 & -0.0524 & 0.0588 & 0.1536 & 0.2799 & -0.1597 & 3.9723 & 10.9097 & $\mathrm{R}$ & 0.0116 \\
\hline UKX Index & -0.0923 & 0.0962 & -0.6465 & 0.4000 & 0.3106 & 6.6233 & 140.7746 & $\mathrm{R}$ & 0.0010 & -0.0668 & 0.0443 & 0.2303 & 0.2622 & -0.2272 & 3.9021 & 10.6280 & $\mathrm{R}$ & 0.0124 \\
\hline \multicolumn{10}{|c|}{2010} & \multicolumn{9}{|c|}{2011} \\
\hline & $\begin{array}{c}\text { Min Daily } \\
\text { Return }\end{array}$ & $\begin{array}{c}\text { Max Daily } \\
\text { Return }\end{array}$ & $\begin{array}{c}\text { Annual } \\
\text { Mean }\end{array}$ & $\begin{array}{c}\text { Annual } \\
\text { std }\end{array}$ & Skewness & Kurtosis & JB & H & $p$-Value & $\begin{array}{c}\text { Min Daily } \\
\text { Return }\end{array}$ & $\begin{array}{c}\text { Max Daily } \\
\text { Return }\end{array}$ & $\begin{array}{c}\text { Annual } \\
\text { Mean }\end{array}$ & $\begin{array}{c}\text { Annual } \\
\text { std }\end{array}$ & Skewness & Kurtosis & JB & $\mathbf{H}$ & $p$-Value \\
\hline FP FP & -0.0427 & 0.0737 & -0.1226 & 0.2254 & 0.1622 & 5.7403 & 79.3164 & $\mathrm{R}$ & 0.0010 & -0.0585 & 0.0476 & -0.0037 & 0.2457 & -0.2340 & 3.7736 & 8.7549 & $\mathrm{R}$ & 0.0197 \\
\hline & -0.09 & & -0.3645 & & & 15.3195 & 1663.5904 & $\mathrm{R}$ & & & & -0.2924 & & & & & $\mathrm{R}$ & 0.0068 \\
\hline VOW3 GY & -0.0629 & 0745 & 0.7057 & 0.3498 & -0.0003 & 3.2736 & 0.7800 & A & 0.5000 & -0.0736 & 0.0994 & -0.0464 & 0.43 & 0.12 & 3.5902 & 4.3738 & A & 0.0893 \\
\hline BNP FP & -0.0770 & & -0.1405 & & & 13.1948 & 1141.6031 & $\mathrm{R}$ & & & & & & & 5.8701 & 91.5016 & $\mathrm{R}$ & 0.0010 \\
\hline DBK GY & -0.0755 & & -0.162 & & & & 193.4445 & $\mathrm{R}$ & 0.00 & -0.0927 & & -0.2762 & & 0.3426 & 6.0348 & 103.6490 & $\mathrm{R}$ & 0.0010 \\
\hline TEF SQ & -0.0761 & & $-0.12 \mathrm{c}$ & & & 13.1 & 1078.5520 & $\mathrm{R}$ & 0.00 & -0.0590 & 0.04 & -0.2306 & 0.2695 & -0.1712 & 4.2022 & 16.7312 & $\mathrm{R}$ & 0.0037 \\
\hline ISP IM & -0.0808 & & -0.3890 & & & 11.3222 & 768.4168 & $\mathrm{R}$ & 0.00 & & & -0.3756 & 0.6431 & -0.5304 & 4.4557 & 34.7431 & $\mathrm{R}$ & 0.0010 \\
\hline ENEL IM & -0.0574 & & -0.0574 & & 0.1074 & 6.9702 & 164.6747 & $\mathrm{R}$ & 0.00 & -0.0816 & & -0.1689 & 0.3213 & -0.4818 & 4.7037 & 41.0263 & $\mathrm{R}$ & 0.0010 \\
\hline & -0.0676 & & & & -0.0866 & & & $\mathrm{R}$ & 0.0494 & -0.1774 & & -0.5406 & & -0.5330 & 8.0922 & 289.8362 & $\mathrm{R}$ & 0.0010 \\
\hline MSFT UW & -0.0407 & 388 & 0.0029 & & -0.2385 & 3.7083 & 7.5948 & $\mathrm{R}$ & 0.0272 & -0.0529 & 0.0433 & -0.0408 & & -0.215 & 4.5799 & 28.7242 & $\mathrm{R}$ & 0.0010 \\
\hline RBS LN & -0.1955 & & & & -0.4706 & & 425.4745 & $\mathrm{R}$ & & & & & & & & 7.9866 & $\mathrm{R}$ & 0.0241 \\
\hline \multirow[t]{2}{*}{ ULVR LN } & -0.0828 & 0.0611 & 0.0314 & 0.2176 & -0.6901 & 9.8276 & 505.4270 & $\mathrm{R}$ & 0.0010 & -0.0272 & 0.0366 & 0.1324 & 0.1687 & 0.1154 & 3.3345 & 1.7682 & A & 0.3672 \\
\hline & \multicolumn{9}{|c|}{ Indexes' Statistics } & \multicolumn{9}{|c|}{ Indexes' Statistics } \\
\hline SPX Index & & & & 0.1642 & -0.2917 & & & $\mathrm{R}$ & & & & & & & & & $\mathrm{R}$ & 0.0010 \\
\hline SX5E Index & -0.0482 & 0.0985 & -0.0503 & 0.2363 & & 10.4500 & 598.9229 & $\mathrm{R}$ & 0.0010 & -0.0654 & 0.0590 & -0.1819 & 0.2885 & & 4.5356 & 27.7334 & $\mathrm{R}$ & 0.0010 \\
\hline UKX Index & -0.0358 & 0.0471 & 0.1329 & 0.1748 & -0.0519 & 4.6341 & 27.9268 & $\mathrm{R}$ & 0.0010 & -0.0466 & 0.0379 & -0.0307 & 0.2004 & -0.3651 & 4.3841 & 26.2260 & $\mathrm{R}$ & 0.0010 \\
\hline
\end{tabular}




\section{Appendix B. Violations and Kupiec's Portion of Failure Test 2008}

Table A2. Violations and Kupiec's POF test for each equity and risk model. The table displays the violations, the POF test statistic (log-likelihood ratio, LR), and the outcome $\left(H_{0}\right)$ for all the stocks and risk models during the 2008 crisis year $(\mathrm{A}=$ accepted and $\mathrm{R}=$ rejected).

\begin{tabular}{|c|c|c|c|c|c|c|c|c|c|c|c|c|c|c|}
\hline & & & \multicolumn{12}{|c|}{ Violations and Kupiec's POF-Test 2008} \\
\hline & & & FP FP & SAN SQ & VOW3 GY & BNP FP & DBK GY & TEF SQ & ISP IM & ENEL IM & C UN & MSFT UW & RBS LN & ULVR LN \\
\hline \multirow{9}{*}{$\operatorname{VaR}$} & \multirow{3}{*}{$1 \%$} & LR & 9.711 & 15.210 & 15.210 & 15.210 & 24.852 & 7.297 & 18.253 & 7.297 & 43.847 & 28.383 & 18.253 & 9.711 \\
\hline & & H0 & $\mathrm{R}$ & $\mathrm{R}$ & $\mathrm{R}$ & $\mathrm{R}$ & $\mathrm{R}$ & $\mathrm{R}$ & $\mathrm{R}$ & $\mathrm{R}$ & $\mathrm{R}$ & $\mathrm{R}$ & $\mathrm{R}$ & $\mathrm{R}$ \\
\hline & & VIOL & 9 & 11 & 11 & 11 & 14 & 8 & 12 & 8 & 19 & 15 & 12 & 9 \\
\hline & \multirow{3}{*}{$2 \%$} & LR & 10.439 & 17.230 & 17.230 & 17.230 & 22.401 & 5.016 & 19.756 & 14.830 & 30.998 & 22.401 & 14.830 & 6.653 \\
\hline & & $\mathrm{H} 0$ & $\mathrm{R}$ & $\mathrm{R}$ & $\mathrm{R}$ & $\mathrm{R}$ & $\mathrm{R}$ & $\mathrm{R}$ & $\mathrm{R}$ & $\mathrm{R}$ & $\mathrm{R}$ & $\mathrm{R}$ & $\mathrm{R}$ & $\mathrm{R}$ \\
\hline & & VIOL & 14 & 17 & 17 & 17 & 19 & 11 & 18 & 16 & 22 & 19 & 16 & 12 \\
\hline & \multirow{3}{*}{$3 \%$} & LR & 13.864 & 35.598 & 22.612 & 13.864 & 25.038 & 6.860 & 35.598 & 18.039 & 27.553 & 27.553 & 13.864 & 4.132 \\
\hline & & H0 & $\mathrm{R}$ & $\mathrm{R}$ & $\mathrm{R}$ & $\mathrm{R}$ & $\mathrm{R}$ & $\mathrm{R}$ & $\mathrm{R}$ & $\mathrm{R}$ & $\mathrm{R}$ & $\mathrm{R}$ & $\mathrm{R}$ & $\mathrm{R}$ \\
\hline & & VIOL & 20 & 29 & 24 & 20 & 25 & 16 & 29 & 22 & 26 & 26 & 20 & 14 \\
\hline \multirow{6}{*}{$\Lambda \mathrm{VaR} 1 \%$ (decreasing) } & \multirow{3}{*}{ linear (VaR 5\%) } & LR & 3.280 & 7.297 & 0.654 & 7.297 & 12.356 & 0.654 & 3.280 & 5.141 & 7.297 & 5.141 & 12.356 & 3.280 \\
\hline & & H0 & A & $\mathrm{R}$ & A & $\mathrm{R}$ & $\mathrm{R}$ & A & A & $\mathrm{R}$ & $\mathrm{R}$ & $\mathrm{R}$ & $\mathrm{R}$ & A \\
\hline & & VIOL & 6 & 8 & 4 & 8 & 10 & 4 & 6 & 7 & 8 & 7 & 10 & 6 \\
\hline & \multirow{3}{*}{ linear (VaR 1\%) } & LR & 0.654 & 3.280 & 0.059 & 7.297 & 9.711 & 0.152 & 0.654 & 3.280 & 7.297 & 1.762 & 12.356 & 0.654 \\
\hline & & H0 & A & A & A & $\mathrm{R}$ & $\mathrm{R}$ & A & A & A & $\mathrm{R}$ & A & $\mathrm{R}$ & A \\
\hline & & VIOL & 4 & 6 & 3 & 8 & 9 & 2 & 4 & 6 & 8 & 5 & 10 & 4.000 \\
\hline \multirow{6}{*}{$\Lambda \mathrm{VaR} 1 \%$ (increasing) } & \multirow{3}{*}{ linear (VaR 5\%) } & LR & 0.059 & 0.152 & 0.059 & 0.654 & 1.762 & 0.152 & 0.654 & 3.280 & 1.762 & 0.654 & 1.762 & 0.654 \\
\hline & & H0 & A & A & A & A & A & A & A & A & A & A & A & A \\
\hline & & VIOL & 3 & 2 & 3 & 4 & 5 & 2 & 4 & 6 & 5 & 4 & 5 & 4 \\
\hline & \multirow{3}{*}{ linear (VaR 1\%) } & LR & 0.059 & 0.152 & 0.059 & 0.654 & 1.762 & 0.152 & 0.654 & 3.280 & 1.762 & 0.654 & 1.762 & 0.654 \\
\hline & & H0 & A & A & A & A & A & A & A & A & A & A & A & A \\
\hline & & VIOL & 3 & 2 & 3 & 4 & 5 & 2 & 4 & 6 & 5 & 4 & 5 & 4 \\
\hline \multirow{6}{*}{$\Lambda \mathrm{VaR} 1.5 \%$ (decreasing) } & \multirow{3}{*}{ linear (VaR 5\%) } & LR & 3.361 & 8.811 & 4.955 & 8.811 & 15.990 & 2.027 & 8.811 & 2.027 & 30.880 & 13.431 & 11.033 & 3.361 \\
\hline & & H0 & A & $\mathrm{R}$ & $\mathrm{R}$ & $\mathrm{R}$ & $\mathrm{R}$ & A & $\mathrm{R}$ & A & $\mathrm{R}$ & $\mathrm{R}$ & $\mathrm{R}$ & A \\
\hline & & VIOL & 8 & 11 & 9 & 11 & 14 & 7 & 11 & 7 & 19 & 13 & 12 & 8 \\
\hline & \multirow{3}{*}{ linear (VaR 1\%) } & LR & 0.987 & 6.779 & 0.289 & 4.955 & 11.033 & 0.229 & 0.289 & 2.027 & 30.880 & 3.361 & 11.033 & 0.987 \\
\hline & & H0 & A & $\mathrm{R}$ & A & $\mathrm{R}$ & $\mathrm{R}$ & A & A & $\mathrm{A}$ & $\mathrm{R}$ & A & $\mathrm{R}$ & A \\
\hline & & VIOL & 6 & 10 & 5 & 9 & 12 & 3 & 5 & 7 & 19 & 8 & 12 & 6 \\
\hline \multirow{6}{*}{$\Lambda \operatorname{VaR} 1.5 \%$ (increasing) } & \multirow{3}{*}{ linear (VaR 5\%) } & LR & 0.229 & 1.143 & 0.229 & 0.003 & 0.289 & 1.143 & 0.003 & 0.987 & 0.289 & 0.003 & 0.289 & 0.003 \\
\hline & & $\mathrm{H} 0$ & A & A & A & A & A & A & A & A & A & A & A & A \\
\hline & & VIOL & 3 & 2 & 3 & 4 & 5 & 2 & 4 & 6 & 5 & 4 & 5 & 4 \\
\hline & \multirow{3}{*}{ linear (VaR 1\%) } & LR & 0.229 & 1.143 & 0.229 & 0.003 & 0.289 & 1.143 & 0.003 & 0.987 & 0.289 & 0.003 & 0.289 & 0.003 \\
\hline & & H0 & A & A & A & A & A & A & A & A & A & A & A & A \\
\hline & & VIOL & 3 & 2 & 3 & 4 & 5 & 2 & 4 & 6 & 5 & 4 & 5 & 4 \\
\hline
\end{tabular}




\section{References}

Artzner, Philippe, Freddy Delbaen, Jean-Marc Eber, and David Heath. 1997. Thinking Coherently. Risk 10: 68-71. Artzner, Philippe, Freddy Delbaen, Jean-Marc Eber, and David Heath. 1999. Coherent Measures of Risk. Mathematical Finance 9: 203-28.

Basel Committee on Banking Supervision. 1996a. Amendment to the Capital Accord to Incorporate Market Risks. Basel: Bank for International Settlements.

Basel Committee on Banking Supervision. 1996b. Supervisory Framework for the Use of Backtesting in Conjunction with the Internal Models Approach to Market Risk Capital Requirements. Basel: Bank for International Settlements.

Basel Committee on Banking Supervision. 2016. Minimum Capital Requirements for Market Risk. Basel: Bank for International Settlements.

Berkowitz, Jeremy, Peter Christoffersen, and Denis Pelletier. 2011. Evaluating Value at Risk Models with Desk Level Data. Management Science 57: 2213-27.

Burzoni, Matteo, Ilaria Peri, and Chiara M. Ruffo. 2017. On the Properties of the Lambda Value at Risk: Robustness, Elicitability and Consistency. Quantitative Finance 17: 1735-43.

Campbell, Sean D. 2005. A Review of Backtesting and Backtesting Procedures. Finance and Economics Discussion Series. Washington: Divisions of Research \& Statistics and Monetary Affairs Federal Reserve Board.

Casella, George, and Roger L. Berger. 2002. Statistical Inference. Duxbury: Duxbury Press.

Christoffersen, Peter. 2010. Encyclopedia of Quantitative Finance-Backtesting. West Sussex: John Wiley and Sons.

Corbetta, Jacopo, and Ilaria Peri. 2017. Backtesting Lambda Value at Risk. European Journal of Finance. doi:10.1080/1351847X.2017.1339105.

Embrechts, Paul, and Marius Hofert. 2014. Statistics and Quantitative Risk Management for Banking and Insurance. Annual Review of Statistics and Its Application 1: 493-514.

Engle, Robert. 2001. GARCH 101: The use of ARCH/GARCH models in applied econometrics. Journal of Economic Perspectives 15: 157-68.

Engle, Robert F., Sergio M. Focardi, and Frank J. Fabozzi. 2008. ARCH/GARCH models in applied financial econometrics. In Handbook of Finance. Hoboken: John Wiley \& Sons, Inc.

Frittelli, Marco, Marco Maggis, and Ilaria Peri. 2014. Risk Measures on P(R) and Value at Risk with Probability/Loss Function. Mathematical Finance 24: 442-63.

Gneiting, Tilmann. 2011. Making and Evaluating Point Forecasts. Journal of the American Statistical Association 106: 746-62.

Jorion, Philippe. 2007. Value at Risk, The New Benchmark for Managing Financial Risk. New York: McGraw-Hill.

Kupiec, Paul. 1995. Techniques for Verifying the Accuracy of Risk Measurement Models. Journal of Derivatives 3 : 73-84.

Samitas, Aristeidis, and Elias Kampouris. 2017. Financial Illness and Political Virus: The Case of Contagious Crises in the Eurozone. International Review of Applied Economics. doi:10.1080/02692171.2017.1394272.

(C) 2018 by the authors. Licensee MDPI, Basel, Switzerland. This article is an open access article distributed under the terms and conditions of the Creative Commons Attribution (CC BY) license (http://creativecommons.org/licenses/by/4.0/). 